\title{
MODELING OF HEAT PROCESSES FOR IMPROVEMENT OF STRUCTURE OF METALS AND ALLOYS BY FRICTION STIR METHOD
}

\author{
A.L. MAJSTRENKO ${ }^{1}$, V.M. NESTERENKOV ${ }^{2}$, V.A. DUTKA ${ }^{1}$, V.A. LUKASH ${ }^{1}$, \\ S.V. ZABOLOTNY ${ }^{1}$ and V.N. TKACH ${ }^{1}$ \\ ${ }^{1}$ V.N. Bakul Institute for Superhard Materials, NASU \\ 2 Avtozavodskaya Str., 04074, Kiev, Ukraine. E-mail: alcon@ism.kiev.ua \\ ${ }^{2}$ E.O. Paton Electric Welding Institute, NASU \\ 11 Bozhenko Str., 03680, Kiev, Ukraine. E-mail: office@paton.kiev.ua
}

\begin{abstract}
Developed was a computer model of temperature field in tool and parts in process of their friction stir welding. Modeling of the temperature field was carried out for both successive stages of welding process, i.e. plunging of pin of tool operating element into part (1st stage) and progressive motion of plunged pin in part (2nd stage). The mathematical model represents itself a nonlinear equation of transient heat conduction, which takes into account progressive pin movement during the 2nd stage of welding. Two constituents describe the heat sources, appearing in welding. The first one considers power of heat sources, caused by friction of tool with parts on contact surfaces, the second one takes into account heat generation, promoted by mechanical deformation of part material. Mathematical modeling and experimental examination of temperature field were carried out for tool from cubic boron nitride (cubonit) and hard alloy as well as copper parts during FSW. Adequacy of developed model was determined based on correlation of numerical and experimental results. It is shown that application of superhard materials (cubonit and hard alloy) for manufacture of tool operating elements gives a possibility to provide thermo-mechanical resistance of tool during welding. A possibility is also shown for increase of strength of welded joints of parts from magnesium alloy ML10, gained as a result of application of FSP for modifying of structure of surface layers in parts to be welded with their further electron beam welding. 27 Ref., 1 Table, 14 Figures.
\end{abstract}

$\boldsymbol{K} \boldsymbol{e} \boldsymbol{y} \boldsymbol{w} \boldsymbol{o r d s}:$ mathematical modeling, friction stir welding, temperature field, tools from superhard materials, structure modification, electron beam welding

Patenting [1] of a method of friction stir welding (FSW) allowed its wide application in different branches of industry for joining of alloys, which are difficult-to-weld using traditional methods (zinc-containing aluminum alloys, copper, magnesium cast alloys); metals and alloys, which do not form eutectics and hard solutions as well as due to its advantages in comparison with other methods of parts joining by welding [2, 3]. FSW is carried out at temperature significantly lower than melting one $\left((0.4-0.5) T_{\text {melt }}\right)$. This results in significant reduction of residual stresses and temperature deformations; refinement of microstructure of joint zone that has positive effect on material strength of the parts in zone of their joining. FSW is mainly used for joining of sheet parts along their contact line or welding-on of one sheet part over another [3, 4].

This method is also distributed and improved due to the necessity of joining of parts from dissimilar materials as well as materials, having high hardness and melting temperature. Welding of such materials requires developing of a tool of more perfect structure [5, 6] and application of materials with increased thermo-mechanical and chemical resistance $[7,8]$ for manufacture of its operating elements. Mathematical modeling and experimental examination of thermal condition of tool and parts during welding $[9,10]$ is relevant for selection of optimum tool structures, relevant welding modes and producing of quality welded joint of parts as a result of FSW. At that mathematical modeling in combination with other types of researches allows for reconstructing the most complete pattern of physical-mechanical processes, appearing in FSW.

Mathematical model of temperature field during FSW. Present work is dedicated to numerical modeling of temperature field during welding-on of copper plates to metallic basis by FSW method using heat-resistant tools from cubonit and hard alloy. The whole FSW process can be conventionally divided on two main stages. During the 1st stage a pin of operating element, rotating with high rate around own axis, is gradually plunged into the parts being welded. At the 2nd stage, the pin, being plunged into the 
parts, keeps rotating around own axis and is successively moved to upper surfaces of the parts in direction determined according to technological conditions till welding completion.

Series of physical-mechanical processes can be observed during FSW. Friction in contact zone takes place at the 1st stage at the beginning of contact of pin to part surface. Elements of pin surface carry particles of part material due to pin rotation and effect of friction force. As a result it is deformed taking a form of material stirring in that part of its volume, which is located close to zone of pin to part contact. Besides, plunging of pin into the part also results in its deformation. Both described phenomena of part deformation took place simultaneously, that result in viscoplastic flow of part material relatively to the surface of operating element. At the 2nd stage, when pin plunged into the part is moved parallel to its surface, friction also takes place over the surface of shoulder to part contact. Stirring of material of the parts occurs in its volume close to the surface of pin to part contact as well as shoulder to part contact.

Significant rise of temperature is observed at both stages as a result of friction in part volume zone, located in the vicinity of pin and shoulder surfaces (zone of thermo-mechanical effect). Effect of friction forces promotes for deformation of part material in this zone and its viscoplastic flow, large mechanical deformations occur. Friction force and deformation of the parts result in intensive heat emission and rise of temperature of operating element and parts, that is a reason of change of physical-mechanical properties of the latter, and in turn, influences the processes of deformation, heat emission and heat transfer.

Therefore, the processes of friction, deformation, viscoelastic flow of part material and heat conduction are interrelated in FSW. Thus, in strict formulation the mathematical modeling of temperature field during FSW requires consideration of problem of heat conduction and problems of viscoelastic flow and deformation connected between them. However, only heat conduction problem can be considered in operational development of computer program, taking into account effect of heat sources, promoted by friction forces and viscoplastic deformation, as well as taking into account pin rotation around own axis and its progressive movement in shoulder with respect to the part.

Results of experimental and theoretical investigations [11-13] show that patterns of distribution of temperature and mechanical loads are not symmetric in respect to $A B C D$ plane (Figure 1),

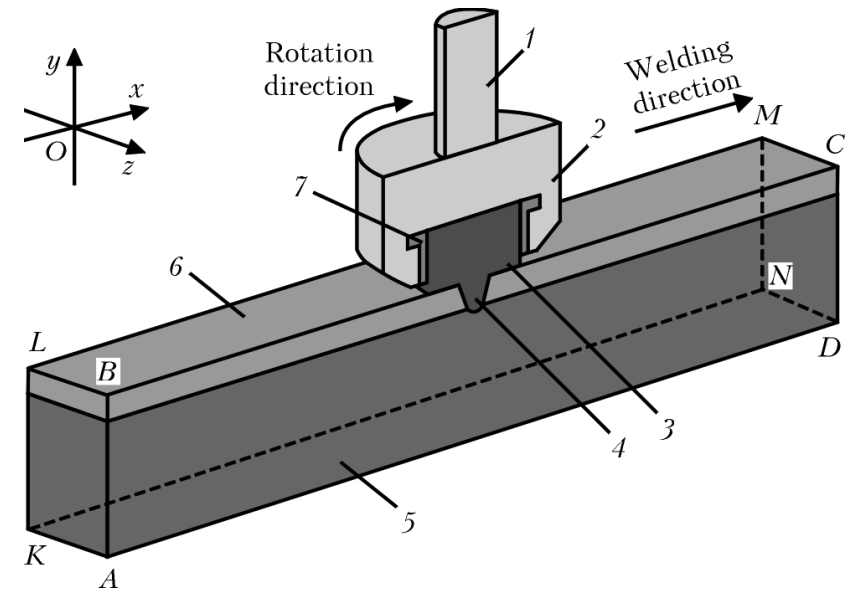

Figure 1. Calculation area (longitudinal section of $A B C D$ plane): 1 - steel shaft of drive; 2 - steel holder; 3,4 shoulder and pin of operating element; 5, 6 - parts to be welded; 7 - hard alloy yoke

which goes through pin rotation axis parallel to welding direction. However, considering that linear rate of pin rotation is 2-3 orders more than its progressive rate, it can be assumed, for simplification of problem formulation and reduction of calculation time, that temperature field in pin with shoulder is symmetric in respect to indicated plane.

Heat transfer equation is used for mathematical modeling of temperature field during FSW:

$$
\rho c_{p}\left(\frac{\partial T}{\partial t}+\vec{v} \operatorname{grad} T\right)=\operatorname{div}(\lambda \operatorname{grad} T),
$$

where $\rho, c_{p}, \lambda$ are the density, specific heat capacity at constant pressure and coefficient of material heat conduction, respectively; $\vec{v}$ is the rate vector; $T$ is the temperature; $t$ is the time.

As indicted in works [10,14], heat emission, produced as a result of deformation of part material during FSW, makes $4.4 \%$ from total heat emission quantity. Considering this as well as taking into account vicinity of part deformation zone to pin with shoulder surface, effect of heat sources, caused by friction and deformation, similarly to $[10,15,16]$ were set in form of effect of general source on surfaces of contact of pin and shoulder to part:

$$
-\lambda \frac{\partial T}{\partial n}=\left[\beta \mu p_{n}+(1-\beta) \eta \tau\right] \omega R,
$$

where $\beta$ coefficient is determined by formula; $p_{n}$ is the normal forces in contact point; $\tau$ is the material yield limit; $\omega$ is the circumferential rate in points of contact surface; $R$ is the distance of studied contact point from pin rotation axis; $\eta$ is the coefficient of mechanical efficiency;

$$
\beta=1-\exp \left(-\frac{\omega R}{\beta_{0} \omega_{0} R_{\mathrm{sh}}}\right),
$$


and its values lies in the ranges from 0 to 1 . Friction coefficient $\mu$ is computed by formula

$$
\mu=\mu_{0} \exp \left(-\lambda_{0} \beta \omega R\right) .
$$

Here $R_{\mathrm{sh}}$ is the shoulder radius; $\omega_{0}$ is the typical value of angular rate; $\mu_{0}$ is the constant value of friction coefficient; $\beta_{0}$ is the constant coefficient with value in $[0 ; 1]$ interval; $\lambda_{0}$ constant equal $1 \mathrm{~s} / \mathrm{m}$. Heat flows are absent in $A B C D$ plane (see Figure 1):

$$
\lambda \frac{\partial T}{\partial n}=0 .
$$

Conditions of convective heat exchange are set on surface of shoulder and part, which contact with external environment of temperature $T_{\text {env }}$ :

$$
-\lambda \frac{\partial T}{\partial n}=\alpha\left(T-T_{\text {env }}\right)
$$

with corresponding value of coefficient of convective heat exchange $\alpha$. Besides, conditions of heat emission according to Stefan-Boltzmann law are set on the surfaces of parts and shoulder, located in the vicinity of zones with high temperature:

$$
-\lambda \frac{\partial T}{\partial n}=\varepsilon \sigma_{0}\left(T^{4}-T_{\mathrm{env}}^{4}\right),
$$

where $\varepsilon$ is the surface emissivity coefficient; $\sigma_{0}$ is the Stefan-Boltzmann constant.

Condition of transfer of heat energy through indicated surfaces are set on the edges of calculation area $A K L B$ and $D N M C$ (see Figure 1), considering progressive movement of parts with rate $\vec{v}$ in relation to pin with shoulder:

$$
-\lambda \frac{\partial T}{\partial n}=c_{p} \rho v_{n}\left(T-T_{0}\right)
$$

where $v_{n}$ is the projection of rate vector $\vec{v}$ on normal line to surface. At the initial moment of time, temperature of calculation area equals room temperature.

As can be seen from equation (1), mass transfer is considered in mathematical formulation of heat conduction problem. Though, due to the fact that rotation rate of pin with shoulder (equal $\omega R \approx 0.1-1.0 \mathrm{~m} / \mathrm{s}$ ) is significantly larger of their progressive speed $v_{\mathrm{w}}$ along welding line $\left(v_{\mathrm{w}}=\right.$ $=0.002-0.004 \mathrm{~m} / \mathrm{s}$ ), the model takes into account these movements in the following way. Temperature field in pin with shoulder is virtually axially symmetric in rotation of pin with shoulder around own axis with large rate. Therefore, heat conduction equation (1) considers only progressive speed of part movement in relation to pin with shoulder, i.e. $v=\left(-v_{\mathrm{w}}, 0,0\right)$.
The mathematical model realizes consideration of pin with shoulder rotation by means of averaging of temperature along each line $L_{i}(i=$ $=1,2, \ldots, N)$ of rotation of surface points of pin and shoulder, where $N$ is the quantity of rotation lines. It has the following computer implementation. Average temperature value $T_{i}$ is computated with the help of corresponding contour integral of the first order after each time step along each rotation line:

$$
\begin{gathered}
T_{i}=\frac{1}{L_{i}} \int_{L_{i}} T(x, y, z, t) d l, \\
\left(\begin{array}{c}
L_{i}=\int_{L_{i}} d L \\
L_{i}
\end{array}\right), \quad i=1,2, \ldots, N .
\end{gathered}
$$

After that, temperature equal $T_{i}$ is taken in each of nodes $T_{i, k}$ lying in this rotation line:

$$
T_{i, k}=T_{i}, \quad k=1,2, \ldots, K_{i},
$$

where $K_{i}$ is the quantity of points of division of $i$-th lines. Boundary conditions of heat transfer are set on the surfaces of contact of part with massive bodies (supports) and shoulder (with drive connection elements) by means of entering of effective heat exchange coefficient $\alpha_{\mathrm{ef}}$ :

$$
-\lambda \frac{\partial T}{\partial n}=\alpha_{\mathrm{ef}}\left(T-T_{\mathrm{env}}\right) .
$$

$\alpha_{\text {ef }}$ value is determined based on equation of heat balance taking into account temperature dependence of thermal-physical properties and geometry parameters of contact bodies.

Finite element method in combination with Bubnov-Galerkin method and time finite-difference scheme of Crank-Nicolson were used for solving of heat conduction problem (1)-(11). The computations were carried out with the help of updated version of software package [17] in Visual Fortran 6.5 medium on modeling of 3D temperature field, where progressive tool movement (second member in the left part of equation (1)) as well as rotation of pin with shoulder (formula (9), (10)) are considered.

The calculation area (see Figure 1) was selected based on size of parts to be welded and indicated above conditions of problem symmetry. $A B C D$ is the symmetry plane. All parts of the calculation area in computer realizing are stationary. However, modeling of movement of those parts, which stir during FSW, is carried out with the help of corresponding developed algorithms, described below .

Modeling of heat sources at the first stage of FSW. Modeling of effect of heat sources at the stage of pin plunging into the parts being 
welded is carried out in the following way. It is assumed that the pin is moved uniformly down during real plunging into the parts. At that, heat sources act on the surface of plunged part of the pin at each moment of time. Computer modeling considers the pin completely plunged into the part (Figure 2), heat sources act only on the surface of part 2 of pin plunged at current moment of time. Modeling of increase of pin plunged part 2 is discrete and made with the help of rise of time step and step of finite-element division of $E F G$ contact surface of pin 2 to part. Calculate area of vertical projection of pin plunged part 2 on plane $x \mathrm{Oz}$ (see Figure 1) at each moment of time depending on pin plunge and compute normal force for each element of surface of pin to part contact.

Plunging of pin promotes for spreading up of area of effect of heat sources in shoulder direction on the surface of pin to part contact, as shown in Figure 2. This stage is finished at the moment of complete plunging of pin into the part.

Modeling of temperature field at the second stage of FSW. Progressive movement of pin with shoulder relatively to parts being welded takes place at this stage of FSW. Modeling of movement of part points with rate $\vec{v}=\left(-v_{\mathrm{w}}, 0,0\right)$, i.e. movement in direction negative to axis $O x$ (see Figure 1), is carried out for realizing of such relative movement. In this case, boundary condition (2) is realized taking into account whole contact surface of pin and shoulder to part. Temperature in the part, which could not exceed its melting temperature $T_{\text {melt }}$, is controlled, similar to pin plunge stage. Condition (8) as well as conditions of axial symmetry of temperature field in pin and shoulder (9), (10) are realized. The rest boundary conditions, indicated in problem formulation, are realized at both stages of FSW.

Results of numerical and experimental investigations of FSW. Developed computer software was used for modeling of temperature field during FSW of copper parts, i.e. upper part 6 is welded on the lower one 5 (see Figure 1). Investigated welded parts were manufactured from copper; pin with shoulder were made from cubonit; yoke produced from hard alloy VK8; holder and shaft of drive were from steel 40 . Dimensions of elements of calculation area were used at computations: radius of pin base made $0.0045 \mathrm{~m}$, height $-0.0065 \mathrm{~m}$; radius of shoulder lower part $-0.0125 \mathrm{~m}$; dimensions of the rest elements are proportional to those indicted in Figure 3. Dimensions of parts were made: upper $0.005 \mathrm{~m}$ thick (being welded-on), lower $0.027 \mathrm{~m}$ thick, length of part make $0.1 \mathrm{~m}$ and width $0.05 \mathrm{~m}$. Since all the parts of calculation spatial

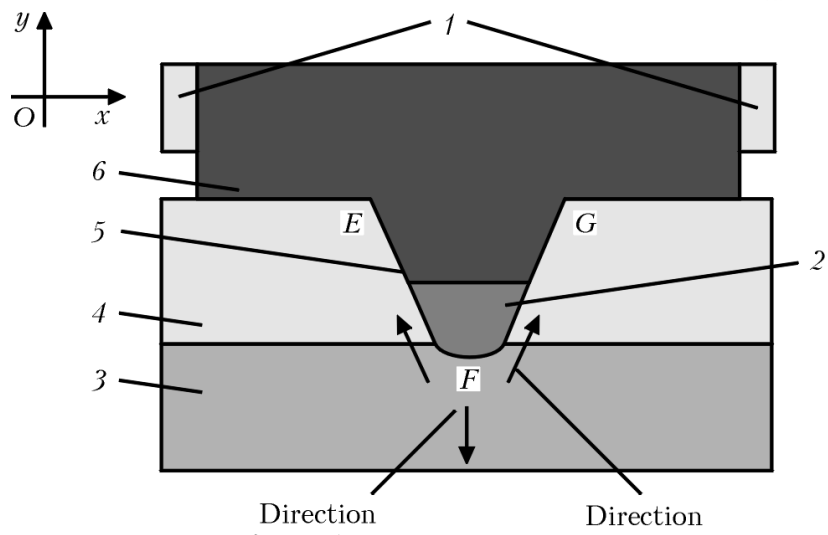

of pin plunge

of heat distribution

Figure 2. Fragment of calculation area for modeling of heat sources at stage of ping plunge into part: 1 - hard alloy yoke; 2 - part of pin volume, plunged into part at specific moment of time; 3, 4 - parts to be welded; 5, 6 - pin and shoulder of operating element, respectively

scheme are stationary in the computer model, then for examination of temperature mode of parts the calculation area of the latter was taken 2 times longer (2 times more in $O x$ axis direction). Pin rotation rate $n_{\text {rev }}=1180 \mathrm{rpm}$ and average welding speed $v_{\mathrm{w}}=0.563 \mathrm{~mm} / \mathrm{s}$.

Thermal-physical properties of copper, cubonit, hard alloy and steel 40 were selected from works [18-21]. Information on temperature dependence of copper yield strength (Figure 4) was taken from [22, 23]. Values of constant parameters are the following: $\mu_{0}=0.4, \beta_{0}=0.4$ and $\lambda_{0}=1 \mathrm{~s} / \mathrm{m}$ were taken similar to [10]; $\omega_{0}=$ $=2 \pi n_{\mathrm{rev}}, R_{\mathrm{sh}}=0.0125 \mathrm{~m}$. Coefficient of convective heat exchange $\alpha$ on upper surface of upper part and side surfaces of both parts was taken equal $20 \mathrm{~W} /\left(\mathrm{m}^{2} \cdot \mathrm{deg}\right)$ by procedure [24].

Boundary conditions of convective $(\alpha=$ $\left.=30 \mathrm{~W} /\left(\mathrm{m}^{2} \cdot \mathrm{deg}\right)\right)$ and radiation $(\varepsilon=0.6)$ heat exchanges with ambient environment at room temperature were set on side surface of steel holder and external surfaces of shoulder and hard

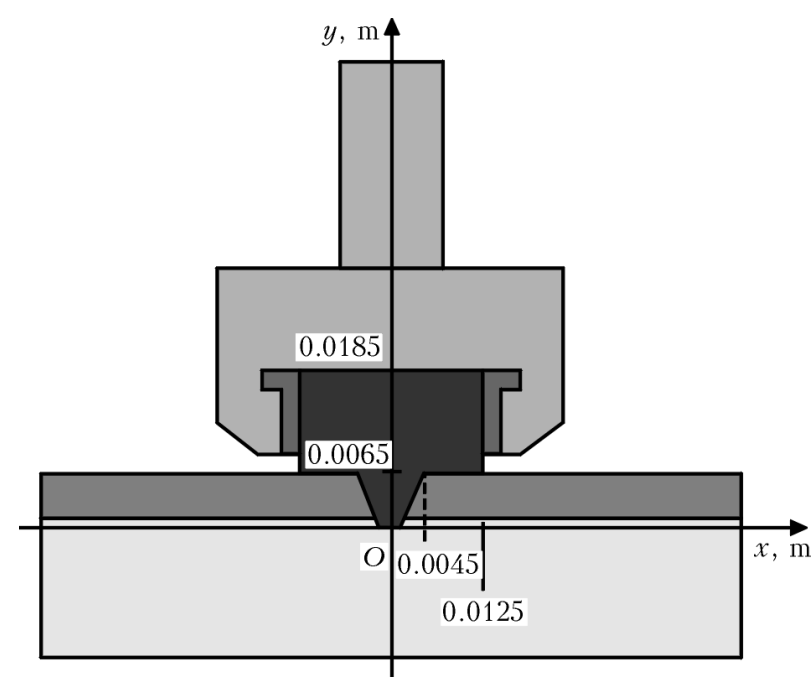

Figure 3. Dimensions of elements of calculation area 


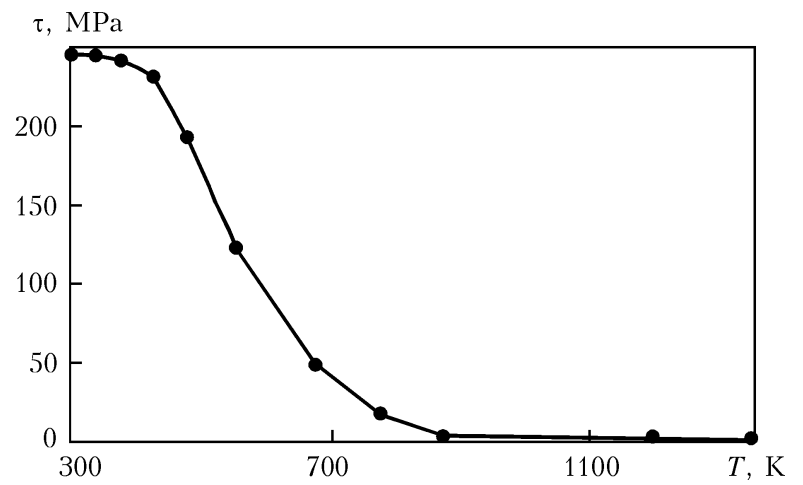

Figure 4. Temperature dependence of copper yield strength

alloy yoke. Boundary conditions of heat exchange with effective coefficient of heat exchange $\alpha_{\mathrm{ef}}$, which is changed depending on temperature in the range of $60-80 \mathrm{~W} /\left(\mathrm{m}^{2} \cdot \mathrm{deg}\right)$, were set on lower surface of lower part, upper surface of steel holder and external surface of drive rod, in the places of contact of indicated elements with massive bodies.

It is obvious fact that temperature field in welding zone significantly depends on technological mode of FSW, in particular, mechanical forces effecting pin with shoulder from drive side. It is necessary to know mechanical stresses on surface of pin and shoulder for determination of power of heat sources. The computer model determines these stresses by mechanical forces effecting pin with shoulder during FSW. There is an experiment on measurement of these forces as well as temperature in separate points of upper part. As can be seen from Figure 5, the 1st stage (pin plunging) is finished for the moment of $124 \mathrm{~s}$. Up to this time, the pin is completely plunged into upper part; the pin is only effected by vertical force, which is gradually reduced and becomes almost 2 times lower its maximum value. Process of welding is started for the moment of 124 s. Pin-shoulder system at this moment of time is effected by tangential force and rise of vertical force is observed, the latter reduces to

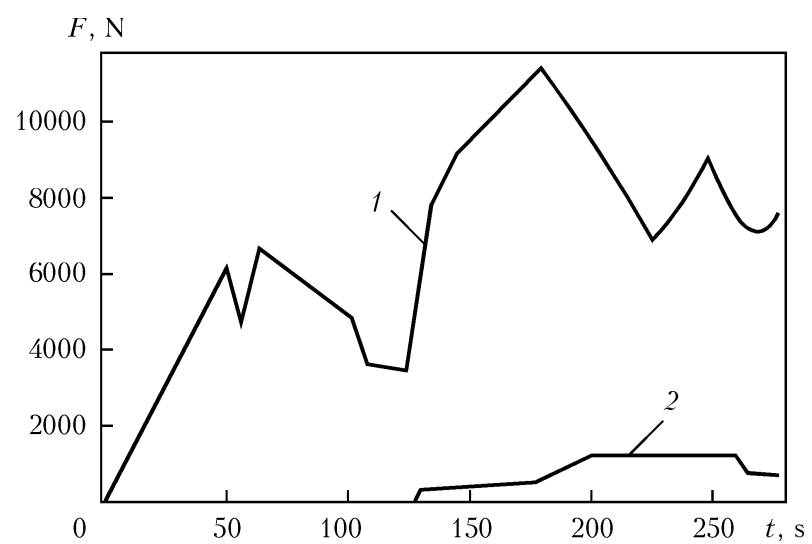

Figure 5. Mechanical loads effecting pin and shoulder during FSW (experiment): 1, 2 - vertical and horizontal constituents of force, respectively

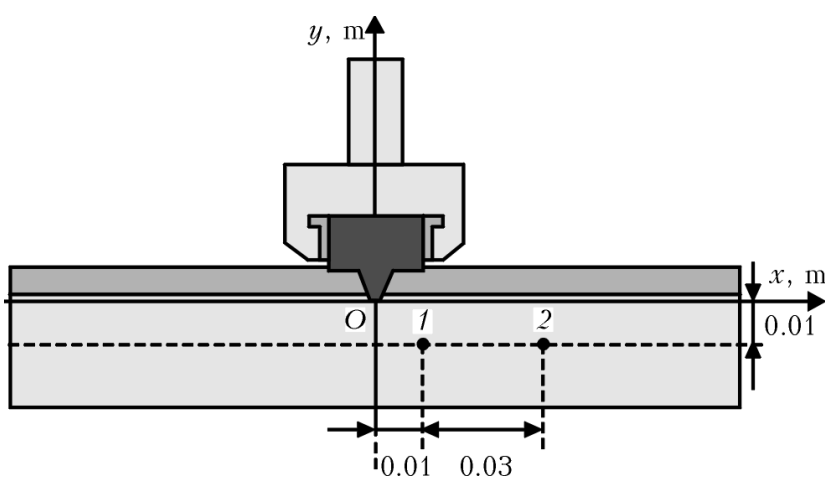

Figure 6. Scheme of positioning of thermocouples $(1,2)$ in temperature measurement during FSW

the end of welding process after achievement of its maximum. In $50 \mathrm{~s}$ after beginning of progressive movement of the parts relatively to the pin, longitudinal feed of machine drive was increased for the purpose of welding speed advance. This results in rise of forces (see Figure 5) effecting the pin with shoulder. Vertical force at the 1st stage of FSW is only applied to the pin and it promotes appearance of heat sources on the surface of pin to part contact. Vertical and horizontal forces are applied to pin as well as shoulder at the 2nd stage; now they are the reason of effect of heat sources on surface of contact of pin to part and shoulder to part. Redistribution of heat sources on the surface of contact of pin and shoulder to part takes place at this stage as can be seen below from computation results.
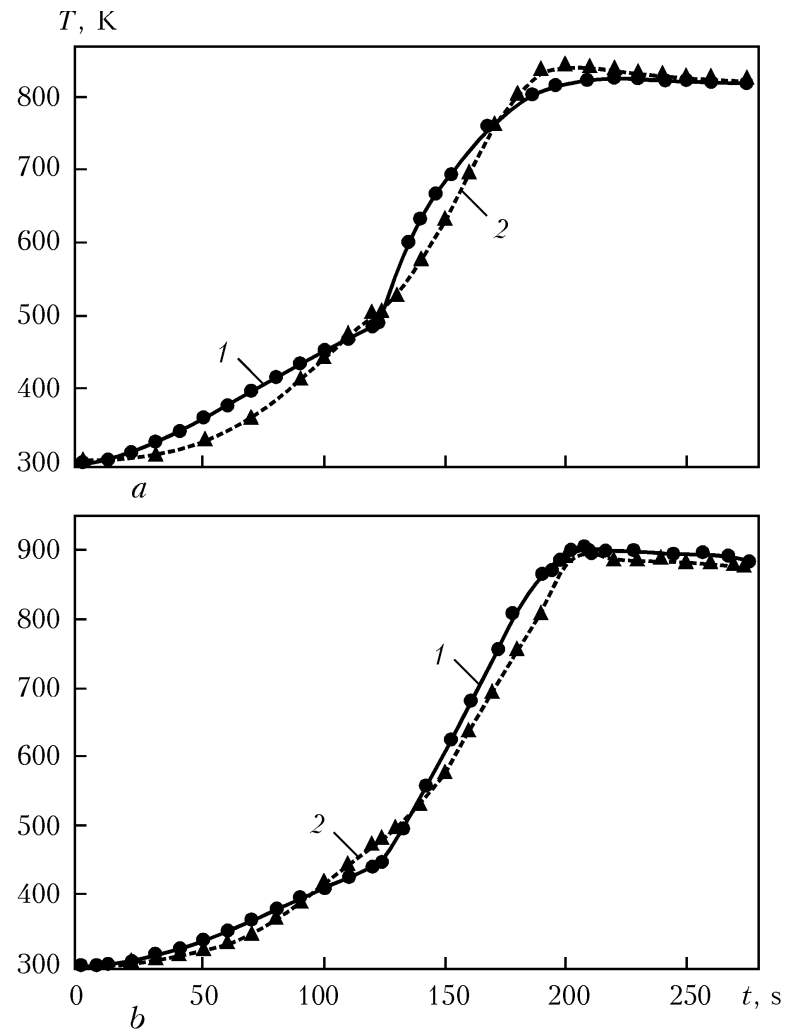

Figure 7. Results of computations (1) and measurement (2) of temperature during FSW: $a, b$ - temperature of the 1st and 2nd thermocouples, respectively 

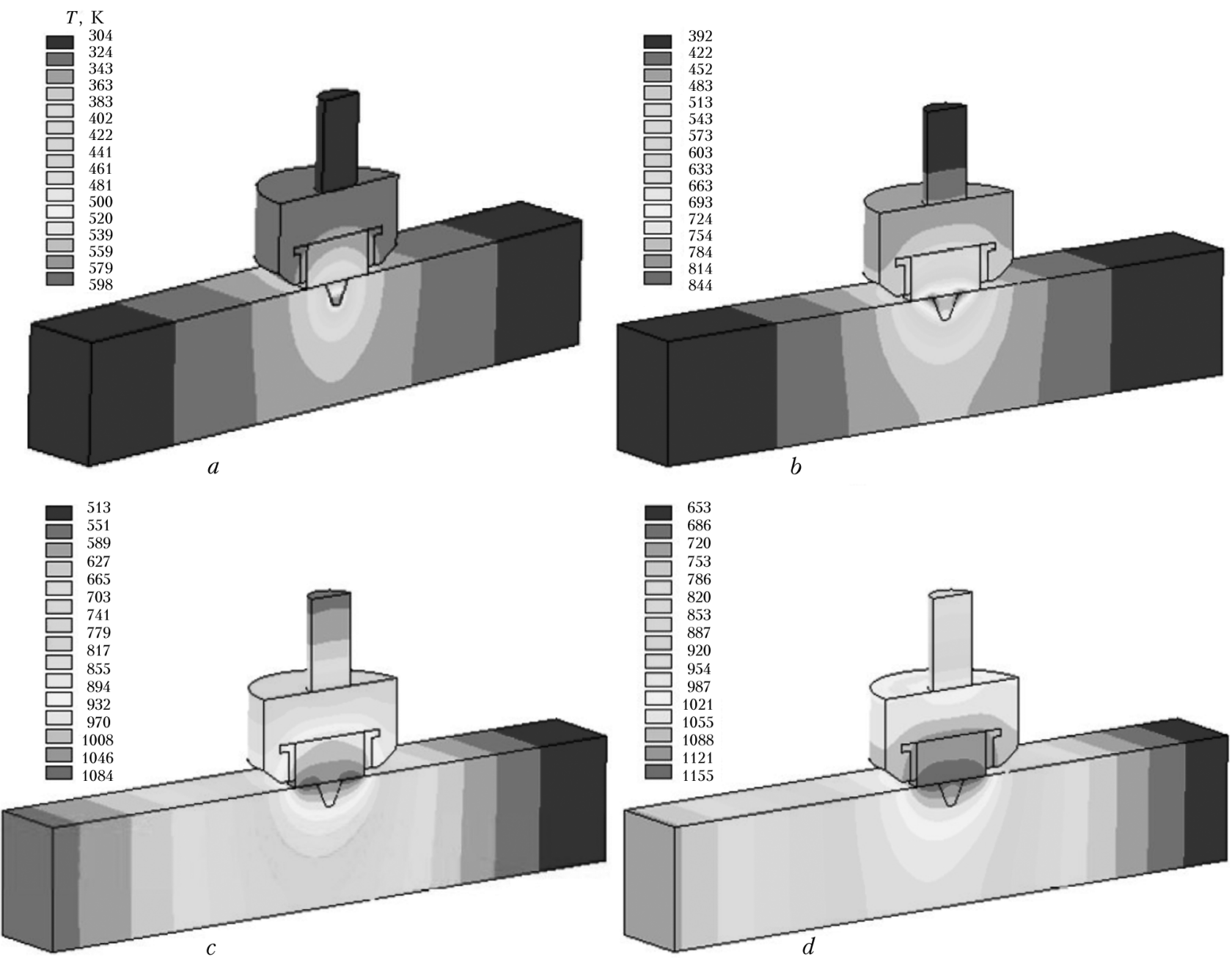

Figure 8. Temperature field at different moments of time: $a-t=60 ; b-124 \mathrm{~s}(1$ st stage of FSW); $c-180 ; d-$ 274 s (2nd stage)

Figure 6 shows a scheme for positioning of thermocouples at the points of $A B C D$ plane (see Figure 1), where temperature during FSW was measured. The results of computer and laboratory experiments are represented in Figure 7 . Their

good agreement can be seen that indicate adequacy of computer model of FSW process.

The results of computations can be used for prediction of condition of temperature field in those zones of investigated area, where the tem-
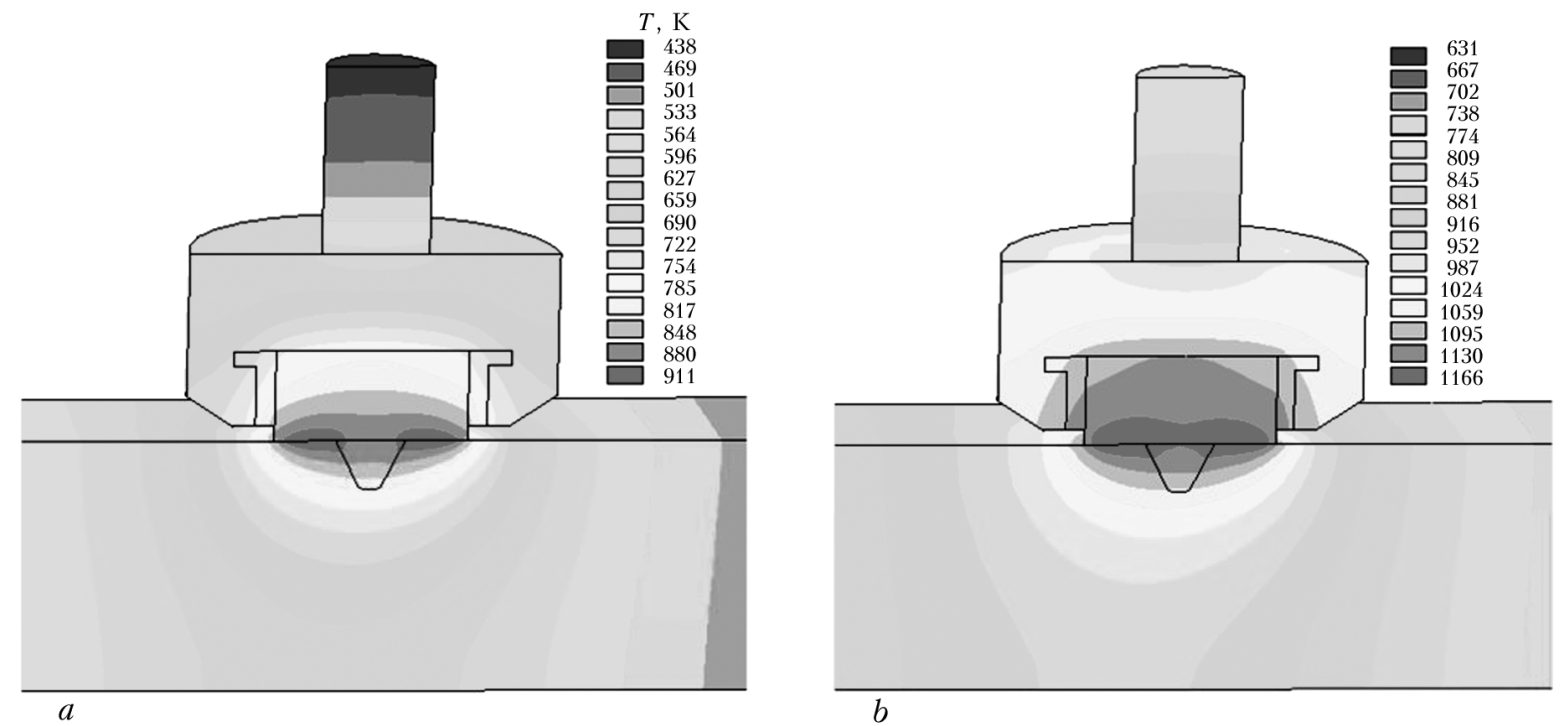

Figure 9. Fragments of patterns of temperature distribution at the 2nd stage of FSW in $25(a)$ and 125 (b) s after beginning of pin horizontal movement 
$T, \mathrm{~K}$

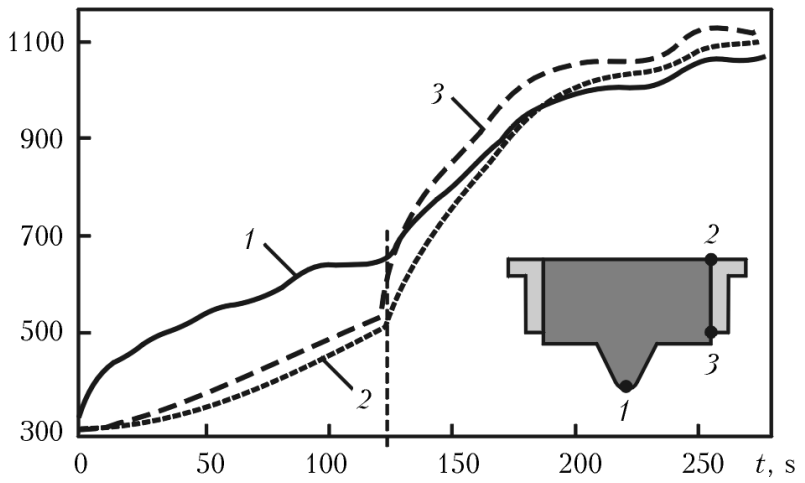

Figure 10. Measurement of temperature in pin tip (1) and two limiting points of surface of hard alloy yoke $(2,3)$ during FSW: vertical dashed line - ending of the 1st stage and beginning of the 2nd stage

perature is difficult or impossible to be measured. Besides, they give the possibility to receive some idea of evolution of temperature field during FSW. Thus, Figure 8 shows the patterns of distribution of temperature in $A B C D$ plane (see Figure 1) in successive discrete moments of time at both stages of FSW process. It can be seen that the maximum temperature lies in the zone of effect of heat sources, caused by friction and deformation of part material. The maximum temperature at the 1st stage depending on pin plunge into the part is gradually shifted from pin tip (its lower point on rotation axis) (Figure $8, a$ ) along its side surface to shoulder plane (Figure 8 , b). The maximum temperature at the moment of stop of pin plunge $(124 \mathrm{~s})$ lies in shoulder zone of joining of pin with shoulder (Figure $8, b$ ). From the moment of complete pin plunge, i.e. at the 2nd stage of FSW process, the zone of maximum temperatures is already on the shoulder surface (Figures $8, c, d ; 9$ ), that agree with the results of other authors $[25,26]$. The main amount of heat is generated in zone of shoulder to part contact at this stage, therefore, the maximum temperature (see Figure 9) is continuously maintained in this zone during the 2nd stage. This information is very important for providing of heat resistance of pin, shoulder as well as yoke (including if its cooling is necessary for prevention of tool overheating). It follows from this

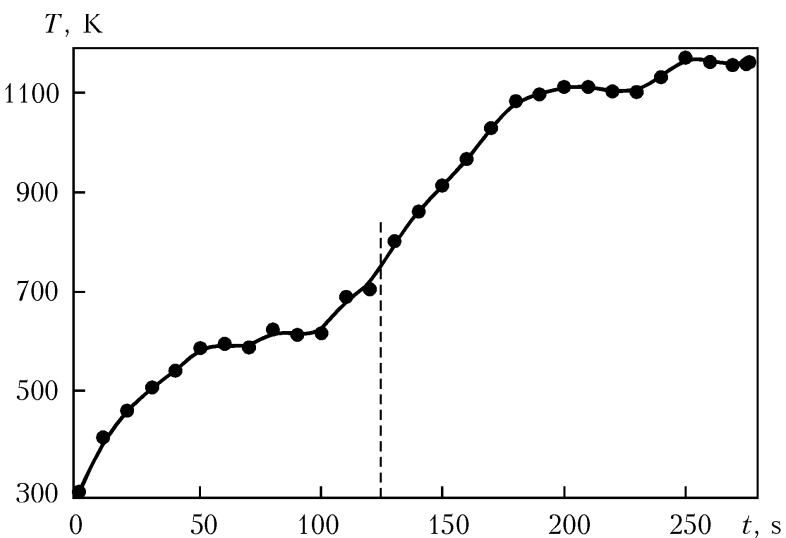

Figure 11. Time change of maximum temperature in operating element during FSW

that heat resistance of shoulder should not be lower than pin heat resistance.

Information on temperature in the most loaded zones of the tool is very important in tool operation under high temperature conditions. Such zones are pin tip, its side surface, shoulder surface being in contact with parts as well as surface of contact of pin with hard alloy yoke. This is also important in computation of heat resistance of tool for FSW. As can be seen from Figure 10, tip of the pin is more heated than surface of hard alloy yoke at the 1st stage. However, heating of the yoke becomes more intensive than pin heating at the beginning of the 2nd stage. Temperature of inner surface of the yoke becomes more than in pin tip and achieves 1090-1130 K level. Difference between this and initial (room) temperature makes $78 \%$ of the difference between copper melting temperature $(1356 \mathrm{~K})$ and room one, that agrees with data of work [2] on temperature in FSW.

According to calculations, total level of thermal (heating to 1090-1130 K temperature) and mechanical loads, mainly promoted by horizontal constituent of force (with maximum value of $1200 \mathrm{~N}$ ), with which the tool effects the part during whole process of welding (see Figure 5, curve 2), are lower than critical one for hard alloy VK6, from which the yoke is manufactured. Thus, compression yield strength for hard alloys VK6 and VK8 in temperature range 1000-1100 K is reduced from 13 to $3 \mathrm{MPa}$ [21] and based on

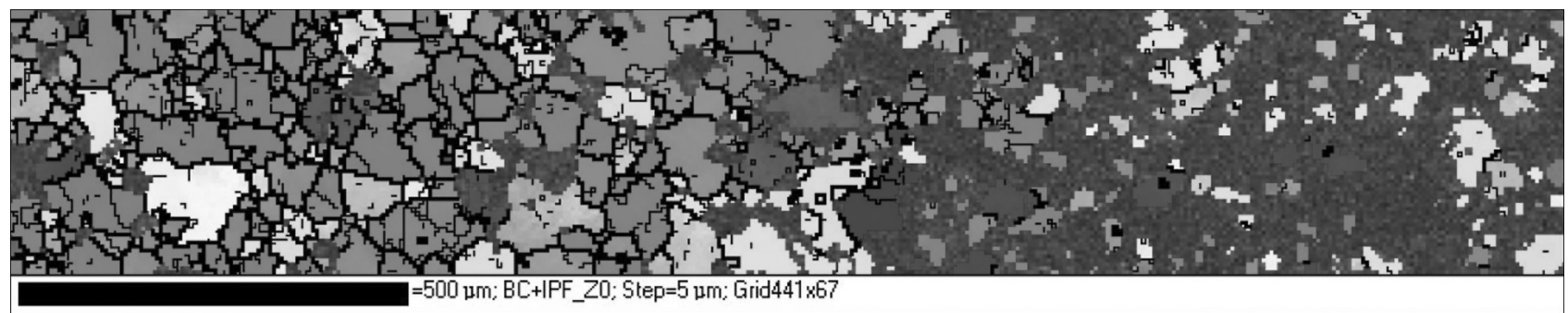

Figure 12. Structure of ML10 alloy at layer boundary in initial and modified conditions (after friction stir processing to $6 \mathrm{~mm}$ depth) 
the results of performed calculations the maximum value of normal pressure on the surface of yoke between points 2 and 3 (see Figure 10) achieves $2.54 \mathrm{MPa}$.

It allows making a conclusion on providing of mechanical durability of the tool from superhard materials for FSW of copper parts in considered welding mode. Obviously that significant increase of horizontal constituent of force (and, thus, speed of progressive pin movement) can result in exceed of yield strength of material of hard alloy yoke for normal forces and as a consequence failure of tool in whole. Therefore, parameters of FSW mode should be thoroughly selected taking into account specific relationship between speed of pin movement and speed of its progressive movement [2].

Temperature in welding zone is very important in selection of material for manufacture of tool operating element using FSW. Material of the operating element should have necessary heat resistance for providing of tool safety. Figure 11 shows that the maximum temperature in operating element is stabilized in 1050-1080 K interval (in copper to copper welding-on). This value is significantly lower than heat resistance of boron nitride, which lies in 1570-1770 K interval [27]. Thus, application of operating element from $\mathrm{cu}_{-}$ bic boron nitride with mentioned above modes of FSW process allows providing resistance of the tool.

Received technological capabilities were also used for modifying of structure of cast magnesium alloy ML10. It happens due to the effect of friction stir process on change of structural condition of surface layer of cast magnesium alloy ML10 parts welded by EBW. Modifying lied in 10-12 times grain refinement of treated layer to $6-8 \mathrm{~mm}$ depth in comparison with base metal. Structure (Figure 12) of samples from ML10 alloy with modified surface layer was examined with the help of scanning electron microscope ZEISS EVO equipped with energy-dispersive analyzer INCA PENTA Fetx3.

Change of parameters of structure of modified samples from magnesium ML10 alloy depends on parameters of tool movement (rates of rotation

Mechanical properties of welded joints of cast magnesium alloy ML10

\begin{tabular}{||l|c|c|c|c||}
\hline \multicolumn{1}{|c|}{ Sample type } & $\sigma_{\mathrm{t}}, \mathrm{MPa}$ & $\sigma_{0.2}, \mathrm{MPa}$ & $\delta, \%$ & $\psi, \%$ \\
\hline Base metal & 230.6 & 140.0 & 5.9 & 11.1 \\
\hline After EBW & 197.9 & 134.3 & 6.5 & 12.0 \\
\hline $\begin{array}{l}\text { After EBW of parts } \\
\text { with surface layers } \\
\text { modified by FSP }\end{array}$ & 216.8 & 153.9 & 6.6 & 12.5 \\
\hline
\end{tabular}

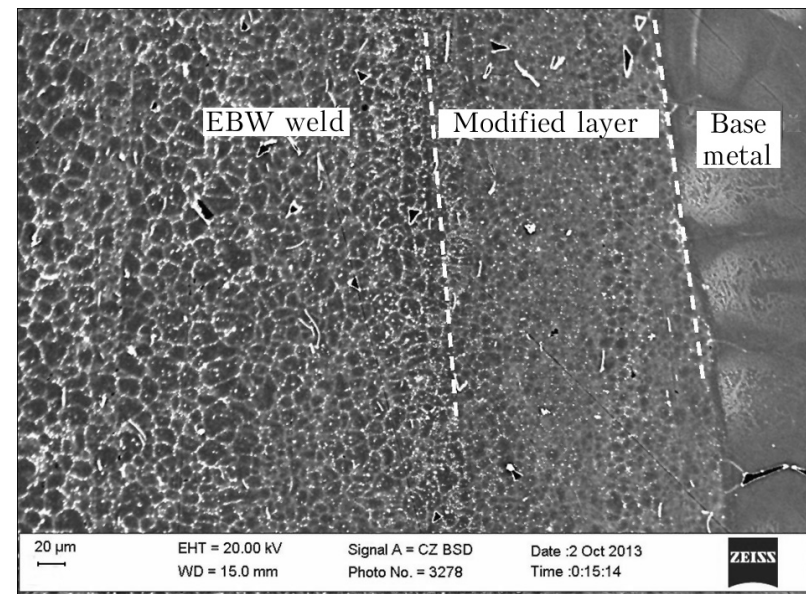

Figure 13. View of structure of welded joint from ML10 alloy with preliminary modification of surface layer $\left(v_{\mathrm{W}}=\right.$ $\left.=20 \mathrm{~mm} / \mathrm{min} ; n_{\mathrm{rev}}=630 \mathrm{rpm}\right)$ and successive EBW

and feed). Image of grain boundaries of mating layers in modified and base metal of alloy ML10, produced by method of diffraction of reflected electrons with the help of scanning electron microscope and shown in Figure 12, indicates high level of effect of modification process on change of alloy structural condition in form of significant 10-12 times grain refinement, i.e. up to $2-3 \mu \mathrm{m}$ size. Namely this peculiarity of structure change of alloy was used for further joining of parts by EBW in vacuum for the purpose of increase of weld strength (Figure 13). The peculiarity was obtained as a result of preliminary modification of surface layer of alloy structure (to $6 \mathrm{~mm}$ depth) using friction stir processing (FSP). Fractographic examination of structure of welded joint using scanning electron microscope showed that due to preliminary FSP of surface layers of part edges with successive EBW, welding already takes place over the alloy with formed finegrained structure (grain size $2-3 \mu \mathrm{m}$, see $\mathrm{Fi}$ gure 13). And alloy grain size in zone of weld metal re-solidification through liquid phase rises only to $5-6 \mu \mathrm{m}$, that $4-5$ times smaller than base

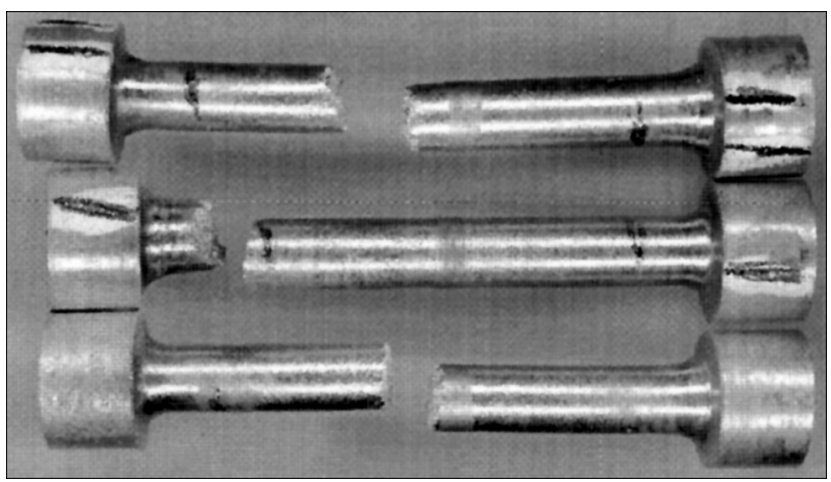

Figure 14. View of samples from alloy ML10 with FSPmodified structure of alloy layers adjacent to welded butt and then being EB-welded $\left(U_{\mathrm{acc}}=60 \mathrm{kV} ; I_{\mathrm{b}}=50 \mathrm{~mA}\right.$; $v_{\mathrm{EBW}}=20 \mathrm{~mm} / \mathrm{s} ; \Delta I_{\mathrm{f}}=5 \mathrm{~mA} ; l_{\mathrm{Op}}=200 \mathrm{~mm}$ ) after mechanical uniaxial tension tests 
metal grain size. However, the main idea is in intermediate structured fine-grained area free of hot cracks forming between re-solidification zone and base metal. Figure 13 shows structure of ML10 alloy in the modified layer as well as conventional boundaries of joining of layers after FSP.

Pull test of welded joints from magnesium alloy ML10 on cylinder samples with test portion diameter $d_{0}=3 \mathrm{~mm}$ was carried out after EBW without application of FSP and after using of hybrid technology (FSP + EBW). The tests showed that samples of ML10 after EBW without FSP fractured along fusion line. An opposite situation is observed in failure of samples treated using hybrid technology (FSP + EBW), i.e. failure takes place out of HAZ (Figure 14).

Results of comparative tensile tests of samples with welded joints, produced by standard EBW method and using hybrid technology (FSP + EBW), confirm its efficiency (see the Table).

\section{Conclusion}

Comparison of computation results and measurement of temperature field in parts to be welded allowed determining an adequacy of model based on its correspondence to experimental data. It is shown that the maximum temperature at welding stage is on shoulder surface that is important in designing of operating elements of tool for FSW. It is also shown that application of such superhard materials as cubic boron nitride and hard alloy, for manufacture of operating elements of the tool designed for FSW, provides for thermo-mechanical resistance of the tool. Developed computer software gives the possibility of on-line prediction of thermal condition during FSW of sheet parts and modifying of structure of light alloys.

Developed tools were used for preliminary FSP of surface layers of cast magnesium alloy ML10 for the purpose of their modifying. The aim of the latter is formation of alloy fine-grained structure (grain size 2-3 $\mu \mathrm{m}$ ) for its further EBW. Alloy grain size as a result of re-solidification of weld metal after EBW grows only to 5-6 $\mu \mathrm{m}$ that is $4-5$ times smaller than base metal grain size. This increases the weld joint strength in comparison with base metal strength.

1. Thomas, W.M., Nicholas, E.D., Needham, J.C. et al Friction stir butt welding. Int. pat. 5,460,317 US. Publ. Dec. 1991

2. Shtrikman, M.M. (2007) State-of-the-art and development of friction welding process of linear joints (Review). Svarochn. Proizvodstvo, 10, 25-32.

3. Zelenin, V.I., Poleshchuk, M.A., Zelenin, E.V. et al (2010) Repair of copper mold plates for steel continuous casting by method of friction stir surfacing. In: Rock cutting and metal-working tools: Technique and technology of its fabrication and application, Issue $13,476-479$.

4. Backer, J.D., Bolmsjo, G., Christiansson, A.K. (2014) Temperature control of robotic friction stir welding using the thermoelectric effect. Int. J. Adv. Manuf. Technol., 70, 375-383.

5. Ding, R.J., Oeigoetz, P.A. Auto-adjustable pin tool for friction stir welding. Pat. 005893507A US. Publ. Apr. 13, 1999.

6. (2007) Friction stir welding and processing. Ed. by R.S. Mishra, M.W. Mahoney. ASM Int. www.asminternational.org.

7. Rai, R., De, A., Bhadeshia, H.K.D.H. et al. (2011) Review: Friction stir welding tools. Sci. and Technol. of Welding and Joining, 16(4), 325-342.

8. Steel, R.J., Peterson, J., Sanderson, S. et al. (2012) Friction stir welding of $20 \mathrm{~mm}$ thickness 1018 steels. In: Proc. of 22nd Int. Offshore and Polar Engineering Conf. (Rhodes, Greece, June 17-22, 2012), 238-243.

9. Buffa, G., Fratini, L., Shivpuri, R. (2008) Finite element studies on friction stir welding process of tailored blanks. Computers and Structures, 86, 181-189.

10. Nandan, R., Roy, G.G., Lienert, T.J. et al. (2007) Three-dimensional heat and material flow during friction stir welding of mild steel. Acta Materialia, 55, 883-895.

11. Threadgill, P.L., Leonard, A.J., Shercliff, H.R. et al. (2009) Friction stir welding of aluminium alloys. Int. Mater. Rev., 54(2), 49-93.

12. Kumbhar, N.T., Bhanumurthy, K. (2008) Friction stir welding of Al6061 alloy. Asian J. Exp. Sci., 22(2), 63-74.

13. Carron, D., Bastid, P., Yin, Y. et al. (2010) Modelling of precipitation during friction stir welding of an Al-Mg-Si alloy. Tech. Mechanik, 30(1-3), 29-44.

14. Bastier, A., Maitournam, M.H., van Dang, K. et al. (2006) Steady state thermomechanical modeling of friction stir welding. Sci. and Technol. of Welding and Joining, 11, 278-288.

15. Yakimov A.V Slobodyanik, P.T Usov, A.V. (1991) Thermal physics of mechanical treatment. Kiev; Odessa: Lybid.

16. Nandan, R., DebRoy, T., Bhadeshia, H.K.D.H. (2008) Recent advances in friction stir welding Process, weldment structure and properties. Progress in Materials Sci., 53, 980-1023.

17. Majstrenko A.L. Dutka, V.A. Pereyaslov, V.P et al. (1999) Mathematical modeling of thermal state of technological assembly unit elements during process of high-speed electric sintering of diamond-containing composite materials. Sverkhtv. Materialy, 4, 26-35.

18. Shulzhenko, A.A., Bozhko, S.A., Sokolov, A.N. et al. (1993) Synthesis, sintering and properties of cubic boron nitride. Kiev: Naukova Dumka.

19. Vargaftik, N.B. (1956) Thermophysical properties of materials: Refer. Book. Moscow; Leningrad: Tekhnoenergoizdat.

20. (1958) Reference book on steels and methods of their tests. Ed. by V.K. Grigorovich. Moscow: Metallurgizdat.

21. Tumanov, V.I. (1971) Properties of alloys of tungsten carbide-cobalt system. Moscow: Metallurgiya.

22. http://www.cniga.com.ua/index.files / cuprum.htm

23. (1976) Tables of physical values: Refer. Book. Ed. by I.K. Kikoin. Moscow: Atomizdat.

24. (1982) Heat and mass exchange. Thermotechnical experiment: Refer. Book. Ed. by V.A. Grigoriev, V.I. Zorin. Moscow: Energoizdat.

25. Uyyuru, R.K., Kailas, S.V. (2006) Numerical analysis of friction stir welding process. J. Materials Eng. and Performance, 15(5), 505-518.

26. Buffa, G., Fratini, L., Micari, F. et al. (2012) On the choice of tool material in friction stir welding of titanium alloys. Proc. of NAMRI/SME, 40,1-10.

27. Lavrinenko, V.I., Smokvina, V.V. Solod, V.Yu. (2013) Peculiarities of morphology of cubic boron nitride powders and their directed application in polishing tools. Such. Tekhnol. v Mashynobuduvanni, Issue 8, 56-65. 